\title{
THERMODYNAMIC RESEARCH ON THE INHIBITORS OF CORONAVIRUS THROUGH DRUG DELIVERY METHOD
}

\author{
FATEMEH MOLLAAMIN * AND MAJID MONAJJEMI
}

\author{
Department of Chemical Engineering, Central Tehran Branch, Islamic Azad University, Tehran, Iran.
}

\begin{abstract}
Based on CoVs, the genomic structure is arranged in a +ssRNA with approximately $30 \mathrm{~kb}$ in length which is the biggest known RNA viruses including a 5 '-cap structure and 3'-poly-A tail. CoVs, (positive stranded RNA viruses), can infect humans and multiple species of animals, cause enteric, respiratory, and central nervous system diseases in many species. These viruses are important for anti-CoV drug delivery through a pivotal function in viral gene expression and replication through the proteolytic processing of replicase polyproteins. In this paper, it has been illustrated the linkage of 6 inhibitors of N-[[4-(4-methylpiperazin-1-yl)phenyl]methyl]1,2-oxazole-5-carboxamide, “inh1”, NSC 158362, “inh2”,JMF 1586 , "inh3”,(N-(2-aminoethyl)-1-1ziridine-ethanamine) , “inh4” ,[(Z)-1-thiophen-2ylethylideneamino]thiourea, "inh5" and Vanillinbananin, "inh6", to CoVs by forming the complexes of "inhibitor- CoV" in water phase through the H-bonding using some physico-chemical properties including heat of formation, Gibbs free energy, electronic energy, charge distribution of active parts in the hydrogen bonding ,NMR estimation of inhibitor jointed to the database amino acids fragment of Tyr-Met-His as the selective zone of the CoV, positive frequency and intensity of different normal modes of these structures. The theoretical calculations were done at various levels of theory in water simulated medium to gain the more accurate equilibrium geometrical results, and infrared spectral data for each of the complex proposed drugs of $\mathrm{N}$-terminal or O-terminal auto-cleavage substrate were individually determined to elucidate the structural flexibility and substrate binding of six inhibitors including jointed to TMH, inh[1-6]-TMH. A comparison of these structures with two configurations provides new insights for the design of substrate-based inhibitors targeting CoV. This indicates a feasible model for designing wide-spectrum inhibitors against $\mathrm{CoV}$-associated diseases.The structure-based optimization of these structures has yielded two more efficacious lead compounds, $\mathrm{N}$ and $\mathrm{O}$ atoms through forming the hydrogen bonding (hydrogen-bonding) with potent inhibition against $\mathrm{CoV}$ (Tyr160-Met161-His162) because of water polar medium which has been abbreviated as TMH in this paper.
\end{abstract}

Keywords: geometry, CoV, inhibitor, TMH, drug delivery, physico-chemical properties, NMR, hydrogen bonding, water, IR, anti-coronavirus.

\section{INTRODUCTION}

Coronaviruses (CoVs) are positive stranded RNA viruses that cause a wide range enteric and central nervous system diseases in multiple species of animals including humans [1-4]. Recently, the relatively low burden of disease in humans caused by few of these viruses hindered the progress of coronavirus specific therapeutics.

Coronavirus disease 2019, COVID-19 which is an contagious disease caused by SARS-CoV-2,[5] close to the SARS virus. [6-10] through small droplets from infected patients while they breathe or cough[11,12]. Between 2 and 14 days, the virus appears with few symptoms or develop fever, cough, and shortness of breath [13,14], but it can be overcome by hygiene substances [15,16].

As a matter of fact, $\mathrm{CoV}$ closely corresponds to intense breathing syndrome $\mathrm{CoV}$ (SARS-CoV) which is an epidemic with short period at its living time. SARS-CoV and MERS-CoV relate to the family Coronaviridae's family as enveloped, positive stranded RNA viruses with around 30,000 nucleotides. It has been reported that the global outbreak of a life-threatening typical pneumonia caused about 800 deaths which was world identified as the harsh syndrome $\mathrm{CoV}$ (SARS-CoV) [17-21]. Moreover, developed investigations have indicated that the origin of SARS-CoV based on the phylogenic analysis is mostly likely from bats which are transferred to human aerosols due to intermediate hosts like infectious palm civets by the virus [22-24].

Thus, the animal disease of $\mathrm{CoV}$ due to its power of intermediate transition into persons is a threat which has been summarized with the novel MERS-CoV suggesting bats and dromedary camels as the storage for this virus [25-30].

Besides, MERS-CoV declares SARS-like symptoms due to human infections including malaise, rigors, fatigues and high fevers, signs like influenza, but it has been seen later developement to a typical pneumonia in most cases [31].

In some researches, it has been discovered that a prototype of the Coronaviridae family is a vain infectious bronchitis virus (IBV) which relates to the genetic group III of $\mathrm{CoV}$, and causes severe economic defeat for the poultry industry in the world [32-35].

Actually, the scientists have not discovered any vaccine or specific antiviral treatment, by management concerning care of symptoms, supportive treatment, and experimental data [36]. The results have shown the sample between $1 \%$ to $3 \%[37,38]$

There are some recommendations form the World Health Organization (WHO) to suspected infectious persons having the coronavirus including; wearing a surgical face mask and seeking medical advice from a doctor. Coronavirus disease was indicated with WHO as a Public Health Emergency of International Concern (PHEIC) in 2019-2020, and then China was declared as a zone of the spread of this virus in 2020 [39-41].
So, in this project, the junction process of six inhibitors including N-[[4-(4methylpiperazin-1-yl)phenyl]methyl]-1,2-oxazole-5-carboxamide (inh1), NSC 158362 (inh2),JMF 1586 (inh3),(N-(2-aminoethyl)-1-1ziridine-ethanamine) (inh4), [(Z)-1-thiophen-2-ylethylideneamino]thiourea (inh5) and Vanillinbananin (inh6) to Coronavirus by forming the complexes of Inhibitor- CoV (inh[1-6]-TM) through the hydrogen bonding (H-bonding) has been estimated using theoretical methods to measure the effect of $\mathrm{H}$-bonding in different linkage of six inhibitors to the chain of Tyr160-Met161-His162. Then, the drug delivery method has been launched on the structures which have been modeled and estimated by nuclear magnetic resonance (NMR) and calculated by infrared (IR) spectroscopy using Gaussian09 at 300K (Scheme 1).

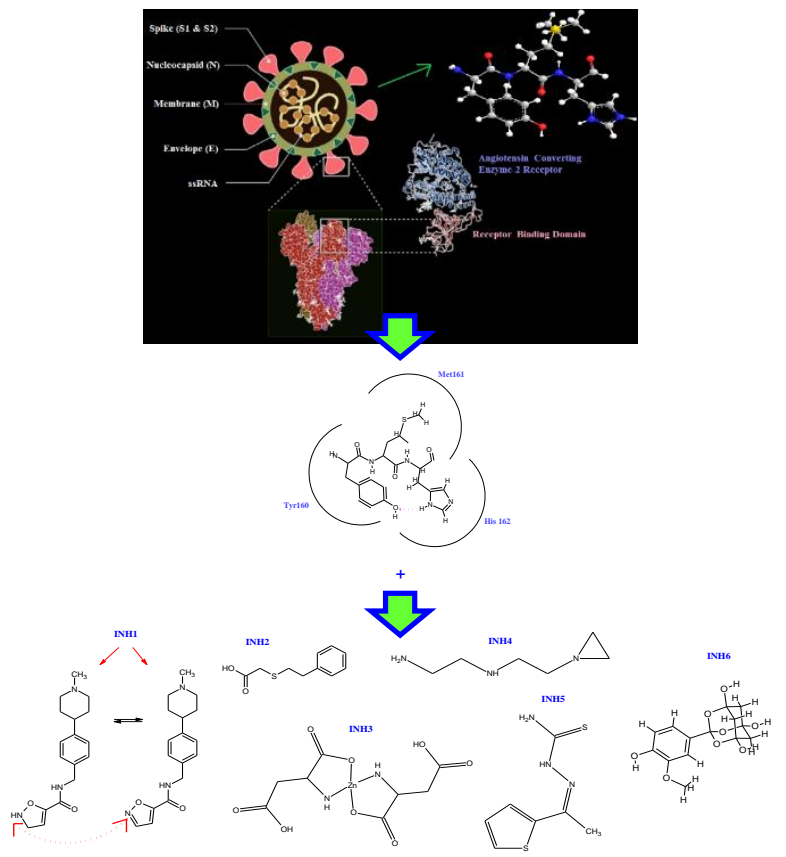

Scheme1. The junction of N-[[4-(4-methylpiperazin-1-yl)phenyl]methyl]-1,2oxazole-5-carboxamide (inh1), NSC 158362 (inh2),JMF 1586 (inh3),(N-(2aminoethyl)-1-1ziridine-ethanamine) (inh4), ,(Z)-1-thiophen-2-ylethylideneamino] thiourea (inh5) and Vanillinbananin (inh6) to TMH (Tyr160-Met161-His162) in water medium by formation the hydrogen bonding. 


\section{Theoretical Background and Methodology}

The junction of N-[[4-(4-methylpiperazin-1-yl)phenyl]methyl]-1,2-oxazole-5carboxamide (inh1), NSC 158362 (inh2),JMF 1586 (inh3),(N-(2-aminoethyl)-11ziridine-ethanamine) (inh4) ,[(Z)-1-thiophen-2-ylethylideneamino]thiourea (inh5) and Vanillinbananin (inh6) to TMH (Tyr160-Met161-His162) has been studied in this investigation by forming relatively stable complexes in water medium through formation the H-bonding. Thus, a series of quantum theoretical approaches of $\mathrm{m} 062 \mathrm{x} / \mathrm{cc}-\mathrm{pvdz}$ pseudo=lanl2 for inh3 (JMF 1586) and pseudo=CEP for other complexes of inh[1-6]-TMH has been done due to finding the optimized coordination of the best structures of inh[1-6]- Tyr160-Met161His162 drug delivery model with IR computations using the Gaussian09 program package [42]. It has been declared that polarization functions into the applied basis set in the computation always introduce us an important
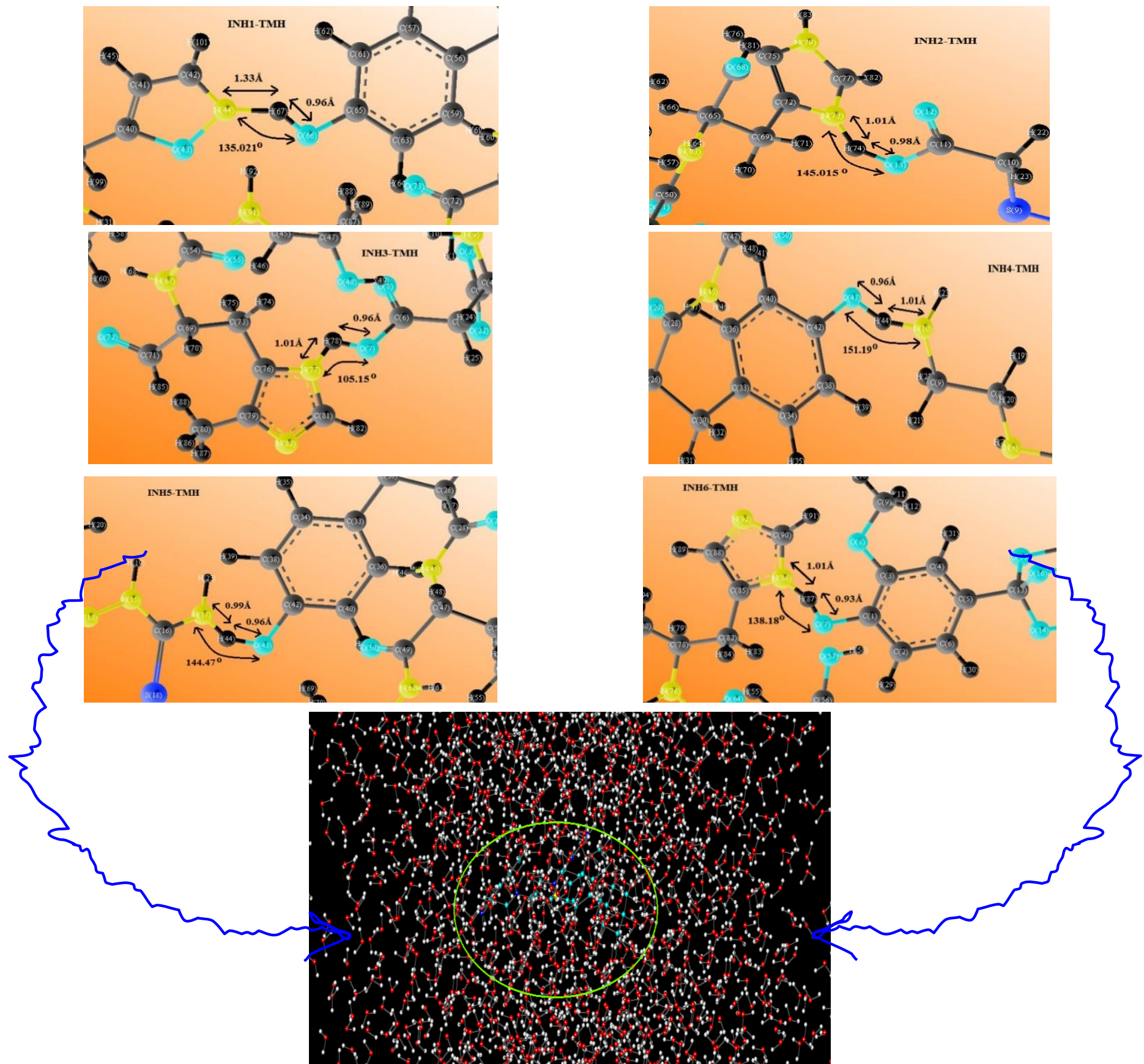

Fig.1. Optimized ab-initio geometry of inh[1-6]-TMH complexes in water as solvent by formation the hydrogen bonding using the drug delivery method by QM/MM model including 3 levels of m06-HF for the high (H) layer, Pm3MM semi empirical for the medium and Monte Carlo for low layers at 300K through

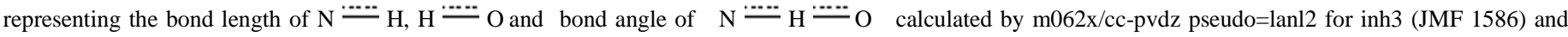
pseudo=CEP for other complexes.

achievement on the modeling and simulation theoretical levels. Normal mode accomplishment is the verdict of harmonic potential wells by analytic methods which maintain the motion of all atoms at the same time in the vibration time scale leading to a natural explanation of molecular vibrations [43-48].

Thus, the optimized geometry coordination of inh[1-6]-TMH complexes (Fig.1) toward the drug delivery method has been done by a series of quantum theoretical approaches of m062x/cc-pvdz pseudo=lanl2 for inh3 (JMF 1586) and pseudo $=\mathrm{CEP}$ for other complexes using the Gaussian09 program package which has shown the active position of indicated oxygen, nitrogen and hydrogen atoms in the junction of bond angles including; $\mathrm{N}(44) \stackrel{\cdots}{-} \mathrm{H}(67) \cdots$ $\mathrm{H}(74) \stackrel{\cdots}{-} \mathrm{O}(13), \mathrm{N}(77) \stackrel{\cdots}{-} \mathrm{H}(78) \stackrel{\cdots}{-} \mathrm{O}(7), \mathrm{N}(10) \stackrel{\cdots}{-} \mathrm{H}(44) \stackrel{\cdots}{-} \mathrm{O}(43)$, $\mathrm{N}(17) \stackrel{\cdots}{-} \mathrm{H}(44) \cdots \mathrm{O}(43), \mathrm{N}(86) \stackrel{\cdots}{-} \mathrm{H}(87) \cdots \mathrm{O}(7)$ for inh[1-6]-TMH, respectively [42] (Table 1).
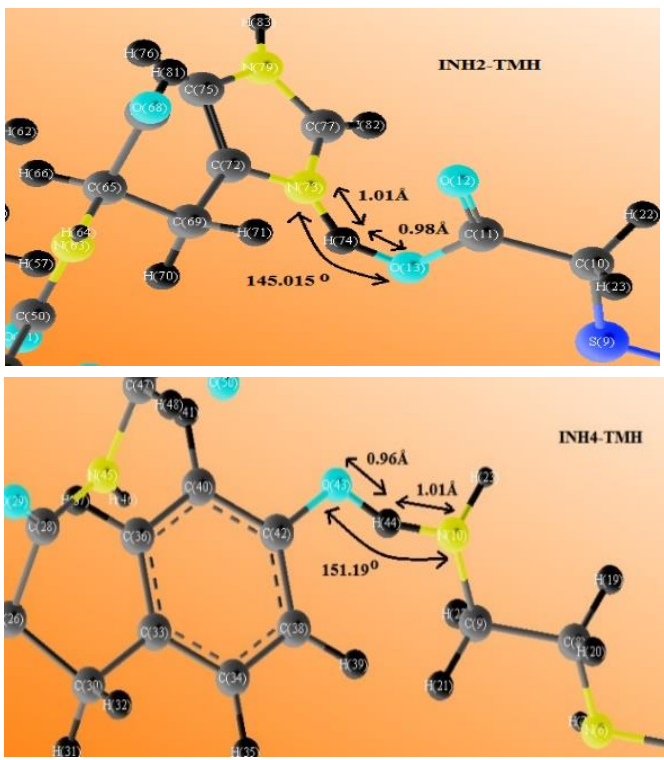
Table 1. Optimized geometry with $\mathrm{m} 062 \mathrm{x} / \mathrm{cc}-\mathrm{pvdz}$ pseudo=lanl2 for inh3 (JMF 1586) and pseudo=CEP for other complexes, inh[1,2-6]-TMH, using the drug delivery method in water medium by formation the hydrogen bonding

\begin{tabular}{|c|c|c|c|c|}
\hline inh - CoVs & Bond length & (Å) & Bond angle & $\left({ }^{\circ}\right)$ \\
\hline \multirow{2}{*}{ inh1-TMH } & $\mathrm{N}(44) \stackrel{\cdots}{=} \mathrm{H}(67)$ & 1.33076 & \multirow{2}{*}{$\mathrm{N}(44) \stackrel{\cdots}{\mathrm{H}(67)} \stackrel{\cdots}{\mathrm{O}} \mathrm{O}(66)$} & \multirow{2}{*}{135.021} \\
\hline & $\mathrm{H}(67) \stackrel{\cdots}{\mathrm{O}(66)}$ & 0.960771 & & \\
\hline \multirow{2}{*}{ inh2 - TMH } & $\mathrm{N}(73) \stackrel{\cdots}{=} \mathrm{H}(74)$ & 1.01017 & \multirow{2}{*}{$\mathrm{N}(73) \stackrel{\cdots}{\mathrm{H}}(74) \stackrel{\cdots}{=} \mathrm{O}(13)$} & \multirow{2}{*}{145.015} \\
\hline & $\mathrm{H}(74) \stackrel{\cdots}{-} \mathrm{O}(13)$ & 0.984098 & & \\
\hline \multirow{2}{*}{ inh3 - TMH } & $\mathrm{N}(77) \stackrel{\cdots}{\mathrm{H}}(78)$ & 1.01017 & \multirow{2}{*}{$\mathrm{N}(77) \stackrel{\cdots}{\mathrm{H}(78)} \stackrel{\cdots}{\mathrm{O}(7)}$} & \multirow{2}{*}{105.147} \\
\hline & $\mathrm{H}(78) \stackrel{\cdots}{=} \mathrm{O}(7)$ & 0.957995 & & \\
\hline \multirow{2}{*}{ inh4 - TMH } & $\mathrm{N}(10) \stackrel{\cdots}{\mathrm{H}(44)}$ & 1.01616 & \multirow{2}{*}{$\mathrm{N}(10) \stackrel{\cdots}{\mathrm{H}(44)} \stackrel{\cdots}{\mathrm{O}(43)}$} & \multirow{2}{*}{151.195} \\
\hline & $\mathrm{H}(44) \stackrel{\cdots}{-} \mathrm{O}(43)$ & 0.960771 & & \\
\hline \multirow{2}{*}{ inh5 - TMH } & $\mathrm{N}(17) \stackrel{\cdots}{\mathrm{H}}(44)$ & 0.990522 & \multirow{2}{*}{$\mathrm{N}(17) \stackrel{\cdots}{\mathrm{H}(44)} \stackrel{\cdots}{\mathrm{O}(43)}$} & \multirow{2}{*}{144.474} \\
\hline & 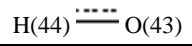 & 0.960771 & & \\
\hline \multirow{2}{*}{ inh6 - TMH } & $\mathbf{N}(86){ }^{\cdots} \mathrm{H}(87)$ & 1.01017 & \multirow{2}{*}{$\mathrm{N}(86) \stackrel{\cdots}{\mathrm{H}(87)} \stackrel{\cdots}{\mathrm{O}(7)}$} & \multirow{2}{*}{138.178} \\
\hline & $\mathrm{H}(87) \stackrel{\cdots}{-} \mathrm{O}(7)$ & 0.929103 & & \\
\hline
\end{tabular}

Besides, the data has been achieved from thermodynamic parameters of $\Delta \mathrm{G}$, $\Delta \mathrm{H}$ and $\Delta \mathrm{S}$ for inh [1-6] - Tyr160-Met161-His162 drug delivery.

Therefore, for accomplishing a stable structure of inh[1-6] linkage of Tyr160Met161-His162, geometry optimization plus the NMR estimation, the frequency and intensity of the vibrational modes were calculated with the quantum mechanical (QM) theoretical method, and the principal vibrational modes were analyzed by their changes of Gibbs free energy in water medium by formation the hydrogen bonding at $300 \mathrm{~K}$.

Thermochemistry analysis follows the frequency and normal mode data. The zero-point energy output in Gaussian-09 has been expanded and corrected as: Thermal correction to energy, thermal correction to enthalpy and thermal correction to the Gibbs free. In addition the total energies can be calculated as: Sum of electronic and zero point energies, sum of electronic and thermal energies, sum of electronic and thermal enthalpies and sum of electronic and thermal Gibbs free energies.

The theoretical calculations were done at various levels of theory to gain the more accurate equilibrium geometrical results and IR spectral data for each of the identified compounds. It is supposed that an additional diffuse and polarization functions into the basis set applied in the computation conduct us to the magnificent progress on the results of theoretical methods.

The simulation indicates the approaches which produce a common template of a model at a special temperature by computing all physicochemical properties among the partition function [44].

Each part of the systems including inh[1-6]-TMH has been optimized using ab-inito via density functional theory including ECP calculations with lanl2 for inh3 (JMF 1586) and pseudo=CEP for inh [1, 2-6]) basis sets. In addition, those systems have been evaluated via QM/MM approach through an ONIOM method. In our study, differences of force fields are debated through comparing density and energies with OPLS and AMBER via Monte Carlo optimization. In addition, a Hyperchem professional release 7.01 program has been applied for some additional keywords such as PM3MM, PM6 (pseudo=lanl2 for inh3 (JMF 1586) and pseudo=CEP for inh $[1,2-6])[49,50]$.

The DFT with the van der Waals densities functional were investigated for modeling of solvent-compounds interaction. All optimization of solvent effects were done by Gaussian 09. The accurate calculations were performed using m062x, m06-L, and m06 for junction of inhibitor to database amino acids interaction. The m062x, m06-L and m06-HF methods have a suitable correspondence in non-bonded calculations between these compounds and solvents. The ONIOM levels have been applied through three levels of high $(\mathrm{H})$, medium (M) and low (L) calculations while DFT methods were used for the high (H) layer and the semi empirical method of pm6 and Pm3MM was used for the medium and finally Monte Carlo for low layers, respectively.

The Polarizable Continuum Model, PCM, is the most popular SCRF model based on apparent surface charges expanding to discuss non-electrostatic impacts using scaled point theory [51, 52].

Rinaldi and Rivail developed the most common levels of the SCRF method of multiple expansions with an algorithm based on the use of a strict multipolar expansion up to the 7th order by Frisch that is currently available at both semiempirical and ab initio levels of theory [53-55].

Onsager and Kirkwood have arranged an intention for various continuum solvation examples of a multiple expansion, MPE, of the solute charge distribution [56-58]. Then, Wiberg and co-workers improved Onsager-SCRF for the Gaussian program $[59,60]$.

Solvation is illustrated in terms of a dipole moment with an iterative path of quantum mechanics calculations on the structure. The perspective of OnsagerSCRF was one to directly apply almost all of the computational characteristics of Gaussian program. The dielectric continuum models like the self-consistent reaction field approach are efficient in applying account the long range of solutesolvent electrostatic interactions and the effect of solvent polarization. Another theoretical level is combination of molecular mechanics (MM) solvent molecule with quantum mechanics level $(\mathrm{QM})$ for electronic structure of the solute molecule named QM/MM which can modify deficiency of the dielectric continuum model [61,62].

\section{RESULTS AND DISCUSSION}

In this project, six inhibitors of $\mathrm{N}$-[[4-(4-methylpiperazin-1-yl)phenyl] methyl]-1,2-oxazole-5-carboxamide (inh1), NSC 158362 (inh2),JMF 1586 (inh3),(N-(2-aminoethyl)-1-1ziridine-ethanamine) (inh4) ,[(Z)-1-thiophen-2ylethylideneamino]thiourea (inh5) and Vanillinbananin (inh6) have been estimated for stabilizing the junction of Tyr160-Met161-His162 as the anticoronavirus through the drug delivery method using IR spectroscopy using Gaussian09 (Fig.1).

Therefore, the thermodynamic properties of $\Delta \mathrm{G}, \operatorname{lnK}, \Delta \mathrm{H}, \Delta \mathrm{S}$, Electronic Energy and Core-Core interaction have determined the stable anti-coronavirus complexes of inh[1-6]-TMH through the H-bonding formation using the drug delivery method (Table2 and Fig.2) in water medium by formation the hydrogen bonding [42].

Table 2. Thermodynamic properties of inh-CoVs complexes; NHI[1-6]-TMH at $300 \mathrm{~K}$.

\begin{tabular}{|c|c|c|c|c|c|c|c|}
\hline inh -CoVs & $\begin{array}{c}\Delta \mathbf{G} \times 10^{-5} \\
(\mathbf{k c a l} / \mathbf{m o l})\end{array}$ & $\ln K$ & $\begin{array}{c}\Delta \mathbf{H} \\
(\mathrm{kcal} / \mathrm{mol})\end{array}$ & $\begin{array}{c}\Delta \mathbf{S} \times 10-^{2} \\
(\text { kcal/K.mol) }\end{array}$ & $\begin{array}{c}\mathbf{E}_{\text {electronic }} \times 10-^{6} \\
(\mathbf{k c a l} / \mathbf{m o l})\end{array}$ & $\begin{array}{c}\mathbf{E}_{\text {core-core }} \times 10^{6}{ }^{6} \\
(\mathbf{k c a l} / \mathbf{m o l})\end{array}$ & $\begin{array}{c}\text { Dipole } \\
\text { (Debyes) }\end{array}$ \\
\hline inh - TMH & 5.8985 & 3.1874 & $7.8303 \times 10^{5}$ & 6.439 & -1.4480 & 2.0379 & 6988.078 \\
\hline inh - TMH & -1.6210 & 2.7173 & $4.3153 \times 10^{2}$ & 5.417 & -1.6899 & 1.5278 & 3.812 \\
\hline inh - TMH & -1.9996 & -5.1237 & $6.4687 \times 10^{2}$ & 6.6869 & -2.1804 & 1.9805 & 12.942 \\
\hline inh - TMH & -1.4563 & 2.4456 & $4.9839 \times 10^{2}$ & 4.8710 & -1.5318 & 1.3862 & 5.612 \\
\hline inh - TMH & -1.5469 & -3.6296 & $6.5336 \times 10^{2}$ & 5.1780 & -1.6677 & 1.5131 & 9.310 \\
\hline inh - TMH & -2.1074 & 16.4390 & $2.4445 \times 10^{2}$ & 7.0329 & -2.4596 & 2.2489 & 14.696 \\
\hline
\end{tabular}


(a)
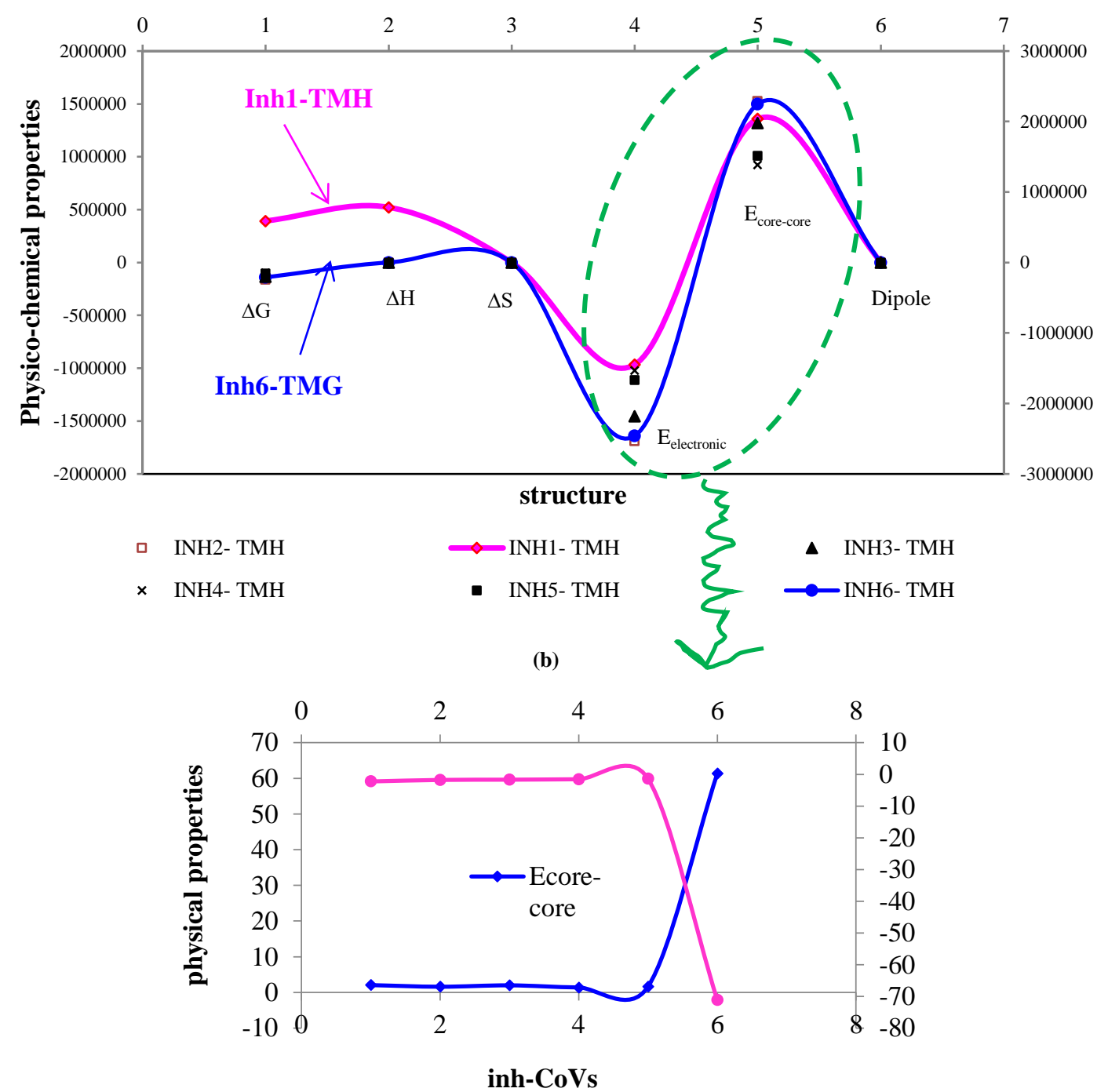

(c)

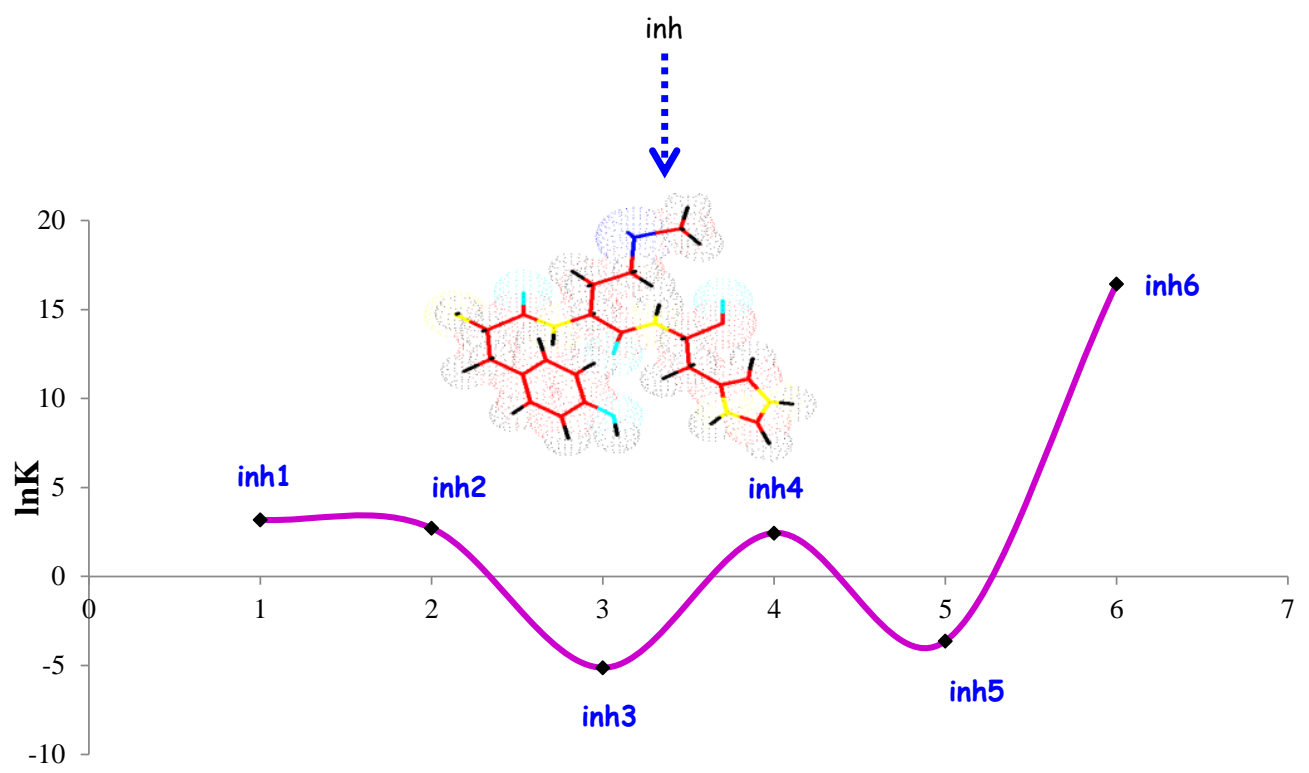

Fig.2. Changes of physico-chemical properties of a) $\Delta \mathrm{G}, \Delta \mathrm{H}, \Delta \mathrm{S}, \mathbf{b}) \mathrm{E}_{\text {electronic }}$ and $\mathrm{E}_{\text {Core-Core }}$ and c) equilibrium constant (lnK) for the stable anti-coronavirus complexes of inh[1-6]-TMH through the H-bonding formation using the drug delivery method in water medium by formation the hydrogen bonding. 
Moreover, the difference of $\Delta \mathrm{H}_{\mathrm{F}}$ among inh[1-6] - TMH has discussed the H-bonding through the six types of inhibitors jointed to the database of amino acids in beta sheet conformation ; Tyr160-Met161-His162 as the active site of the coronavirus(CoV) families (Table 3 , Fig.3a,b).

Table 3. The Heat of formation, $\Delta \mathrm{H}_{\mathrm{F}}$, among inh [1-6] -TMH (kcal/mol) in water medium by formation the hydrogen bonding.

\begin{tabular}{|c|c|c|c|}
\hline \multirow{6}{*}{ 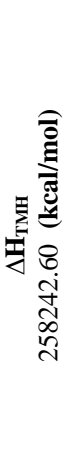 } & $\begin{array}{r}\Delta \mathbf{H}_{\text {inh1 }} \\
1756.03\end{array}$ & $\begin{array}{l}\Delta \mathbf{H}_{\text {(inh1-TMH) }} \\
783032.84\end{array}$ & $\begin{array}{c}\Delta \mathbf{H}_{\mathbf{F}}=\Delta \mathbf{H}_{\text {(inh1-TMH) }}-\left(\Delta \mathbf{H}_{\mathrm{TMH}}+\Delta \mathbf{H}_{\text {inh1 } 1}\right) \\
523034.20\end{array}$ \\
\hline & $\begin{array}{c}\Delta \mathbf{H}_{\text {inh2 }} \\
2.11\end{array}$ & $\begin{array}{c}\Delta \mathbf{H}_{\text {(inh2-TMH) }} \\
431.53\end{array}$ & $\begin{array}{c}\Delta \mathbf{H}_{\mathbf{F}}=\Delta \mathbf{H}_{\text {(inh2- TMH) }}-\left(\Delta \mathbf{H}_{\mathrm{TMH}}+\Delta \mathbf{H}_{\text {inh2 }}\right) \\
-257813.19\end{array}$ \\
\hline & $\begin{array}{l}\Delta \mathbf{H}_{\text {inh3 }} \\
102.56\end{array}$ & $\begin{array}{l}\Delta \mathbf{H}_{\text {(inh3-TMH) }} \\
\quad 646.87\end{array}$ & $\begin{array}{c}\Delta \mathbf{H}_{\mathrm{F}}=\Delta \mathbf{H}_{(\mathrm{inh3}-\mathrm{TMH})}-\left(\Delta \mathbf{H}_{\mathrm{TMH}}+\Delta \mathbf{H}_{\mathrm{inh} 3}\right) \\
-257698.28\end{array}$ \\
\hline & $\Delta \mathbf{H}_{\text {inh4 }}$ & $\Delta \mathbf{H}_{\text {(inh4-TMH) }}$ & $\Delta \mathbf{H}_{\mathbf{F}}=\Delta \mathbf{H}_{(\mathrm{inh} 4-\mathrm{TMH})}-\left(\Delta \mathbf{H}_{\mathrm{TMH}}+\Delta \mathbf{H}_{\mathrm{inh} 4}\right)$ \\
\hline & $\Delta \mathbf{H}_{\mathrm{inh} 4}$ & $\Delta \mathbf{H}_{\text {(inh4-TMH) }}$ & $\Delta \mathbf{H}_{\mathrm{F}}=\Delta \mathbf{H}_{(\mathrm{inh} 4-\mathrm{TMH})}-\left(\Delta \mathbf{H}_{\mathrm{TMH}}+\Delta \mathbf{H}_{\mathrm{inh} 4}\right)$ \\
\hline & $\Delta \mathbf{H}_{\text {inh4 }}$ & $\Delta \mathbf{H}_{\text {(inh4-TMH) }}$ & $\Delta \mathbf{H}_{\mathrm{F}}=\Delta \mathbf{H}_{(\mathrm{inh} 4-\mathrm{TMH})}-\left(\Delta \mathbf{H}_{\mathrm{TMH}}+\Delta \mathbf{H}_{\mathrm{inh} 4}\right)$ \\
\hline
\end{tabular}

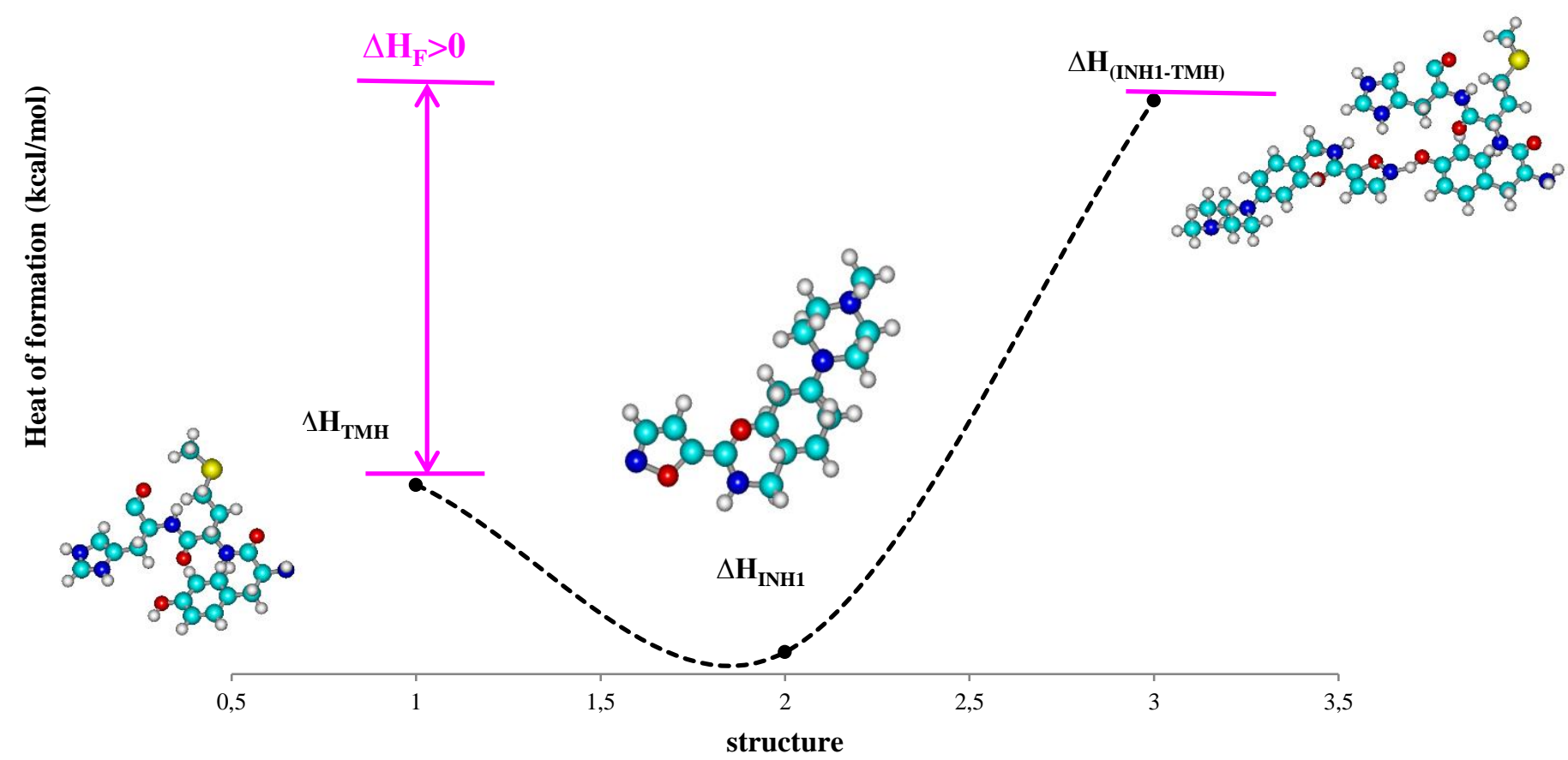

Fig.3. The difference of $\Delta \mathrm{H}_{\mathrm{F}}$ among inh1-TMH and in water medium by formation the hydrogen bonding.

In all six types of inhibitors jointed to the database of amino acids in beta sheet conformation, Tyr160-Met161-His162, as the active site of the coronavirus(CoV) families in the process of drug delivery, the frequency and intensity of various infrared normal modes of inh[1-6]-TMH complexes have been found to be significantly different through the stability of $\mathrm{H}$-bonding formed between active site of $\mathrm{CoV}$ and inhibitors which founds the anti-coronavirus (table 4 \& Fig.4).

Table 4. Calculated frequency and intensity of inh[1-6] -TMH in different normal modes of infrared spectra in water medium by formation the hydrogen bonding.

\begin{tabular}{|c|c|c|c|c|}
\hline inhibitor & complex & Normal mode & Frequency $(1 / \mathrm{cm})$ & Intensity $(\mathbf{k m} / \mathbf{m o l})$ \\
\hline N-[[4-(4-methylpiperazin-1-yl)phenyl]methyl]-1,2-oxazole-5-carboxamide & (inh1-TMH) & 288 & 7357.36 & 4354666.00 \\
\hline NSC 158362 & (inh2-TMH) & 231 & 5285.11 & 986.74 \\
\hline JMF 1586 & (inh3-TMH) & 243 & 5285.71 & 752.09 \\
\hline (N-(2-aminoethyl)-1-1ziridine-ethanamine) & (inh4-TMH) & 228 & 5284.54 & 1222.69 \\
\hline [(Z)-1-thiophen-2-ylethylideneamino]thiourea & (inh5-TMH) & 219 & 5295.18 & 20233.93 \\
\hline Vanillinbananin & (inh6-TMH) & 270 & 5285.84 & 751.27 \\
\hline
\end{tabular}




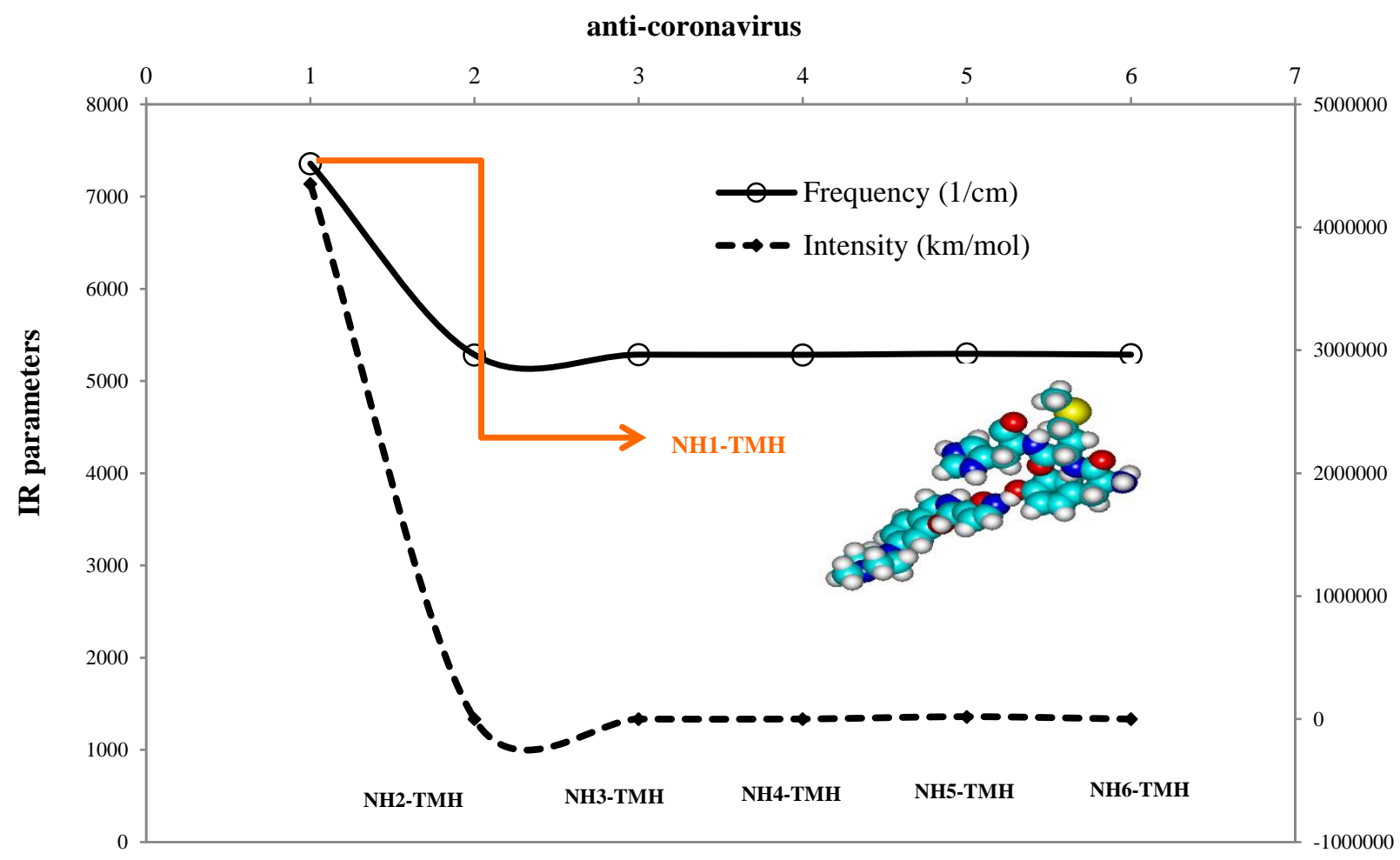

Fig.4. Changes of calculated frequency and intensity versus anti-coronavirus drugs of inh[1-6]-TMH in different normal modes of infrared spectra in water medium by formation the hydrogen bonding.

The frequency and intensity TMH-junction were found to be significantly different with each inhibitor treatment including; $\mathrm{N}$-[[4-(4-methylpiperazin-1-yl) phenyl] methyl]-1, 2-oxazole-5-carboxamide, NSC 158362, JMF 1586, (N-(2aminoethyl)-1-1ziridine-ethanamine), [(Z)-1-thiophen-2-ylethylideneamino] thiourea and Vanillinbananin as (inh[1-6]).

It has been seen that by increasing the activity of atoms in the active site of inhibitors, the frequency and intensity of inh[1-6]-Tyr160-Met161-His162 junction also have increased from 5285.84 to $7357.361 / \mathrm{cm}$ and from 751.2703 to $4354666.00 \mathrm{~km} / \mathrm{mol}$, respectively, in water medium by formation the hydrogen bonding (Table $4 \&$ Scheme2 ).

Although we have little information about the interaction of inhibitors with CoV, database amino acids fragment of Tyr160-Met161-His162 as the selective zone of the $\mathrm{CoV}$ were found to induce frequency and intensity of spectra.

The maximum positive frequency and intensity have been shown for N-[[4-(4methylpiperazin-1-yl)phenyl]methyl]-1,2-oxazole-5-carboxamide(7357.361/cm and $4354666.00 \mathrm{~km} / \mathrm{mol}$ ) jointed to database of amino acids in beta sheet conformation (Tyr160-Met161-His162) with abbreviation of (inh-TMH) which has the largest amount as the anti-coronavirus in the spectrum data (Table $4 \&$ Fig.4).

Similar trends occurred in other inh[2-6]-TMH complexes exhibit the smallest changes in the infrared spectra where the $\mathrm{F}_{\max }$ of junction for NSC 158362, JMF 1586, (N-(2-aminoethyl)-1-1ziridine-ethanamine), and Vanillinbananin were $5285.11,5285.71,5284.54,5295.18$, and $5285.841 / \mathrm{cm}$, respectively (Fig.4). The intensity of IR spectra for NSC 158362, JMF 1586, (N-(2-aminoethyl)-11ziridine-ethanamine), and Vanillinbananin were reported as 986.7394, $752.0885,1222.6909,20233.9316$, and $751.2703 \mathrm{~km} / \mathrm{mol}$, respectively which have approved the stability of these structures anti-coronavirus using the drug delivery method (Table 4).

The frequency achieved of IR vibrational spectra have shown that the normal mode of the active sites due to $\mathrm{F}_{\max }$ for TMH linked to inhibitors of N-[[4-(4methylpiperazin-1-yl) phenyl] methyl]-1,2-oxazole-5-carboxamide, NSC 158362, JMF 1586, (N-(2-aminoethyl)-1-1ziridine-ethanamine), [(Z)-1thiophen-2-ylethylideneamino] thiourea and Vanillinbananin were reported $288,231,243,228,219$, and 270, respectively (Table 4).
In the next step, the atomic charge of indicated atoms of oxygen, nitrogen and hydrogen in the junction of $\mathrm{N}$-[[4-(4-methylpiperazin-1-yl) phenyl] methyl]-1,2oxazole-5-carboxamide, NSC 158362, JMF 1586, (N-(2-aminoethyl)-11ziridine-ethanamine), [(Z)-1-thiophen-2-ylethylideneamino] thiourea and Vanillinbananin with Tyr160-Met161-His162 have been evaluated in the zone of H-bonding formation (Fig.1 \& table 5).

Then, in Fig.5, it has been plotted the changes of atomic charge for labeled oxygen, nitrogen and hydrogen atoms through optimized inh[1-6]-TMH complexes (Fig.1) due to formation of H-bonding ; so, the results of table 5 in a polar zone have declared the stability of anti-coronavirus drugs which have been modeled using the drug delivery method

The largest fluctuation in Fig.5 has been seen for the sample of N-[[4-(4methylpiperazin-1-yl) phenyl] methyl]-1,2-oxazole-5-carboxamide- Tyr160Met161-His162 (inh1-TMH) considering the oxygen and nitrogen as the electronegative atoms and hydrogen in water medium by formation the hydrogen bonding through using the drug delivery method which has proposed the modeling of anti-coronavirus. These results have approved the values of IR spectra for inh1-TMHin and inh[2-6] TMH in Table 4 \& Fig.4.

Table 5. The amounts of atomic charge for labeled oxygen, nitrogen and hydrogen atoms in the junction of $\mathrm{N}$-[[4-(4-methylpiperazin-1-yl) phenyl] methyl]-1,2-oxazole-5-carboxamide, NSC 158362, JMF 1586, (N-(2aminoethyl)-1-1ziridine-ethanamine), [(Z)-1-thiophen-2-ylethylideneamino] thiourea and Vanillinbananin with Tyr160-Met161-His162 (INH[1-6]-TMH) in water medium by formation the hydrogen bonding.

\begin{tabular}{|l|c|c|c|c|c|}
\hline inh1-CoV & charge & inh2-CoV & charge & inh3-CoV & charge \\
\hline $\mathbf{N}(\mathbf{4 0})$ & -3.0 & $\mathbf{N}(\mathbf{7 3})$ & -0.04 & $\mathbf{N}(\mathbf{7 7})$ & 0.22 \\
\hline $\mathbf{H}(\mathbf{6 3})$ & -1.0 & $\mathbf{H}(\mathbf{7 4})$ & 0.30 & $\mathbf{H}(\mathbf{7 8})$ & 0.32 \\
\hline $\mathbf{O}(\mathbf{6 2})$ & -1.9 & $\mathbf{O}(\mathbf{1 3})$ & -0.46 & $\mathbf{O}(\mathbf{7})$ & -0.38 \\
\hline inh4-CoV & charge & inh5-CoV & charge & inh6-CoV & charge \\
\hline $\mathbf{N}(\mathbf{1 0})$ & -0.19 & $\mathbf{N}(11)$ & -0.33 & $\mathbf{N}(\mathbf{8 6})$ & 0.08 \\
\hline $\mathbf{H}(\mathbf{4 4})$ & 0.25 & $\mathbf{H}(\mathbf{4 1})$ & 0.33 & $\mathbf{H}(\mathbf{8 7})$ & 0.29 \\
\hline $\mathbf{O}(\mathbf{4 3})$ & -0.27 & $\mathbf{O}(\mathbf{4 0})$ & -0.32 & $\mathbf{O}(\mathbf{7})$ & -0.25 \\
\hline
\end{tabular}




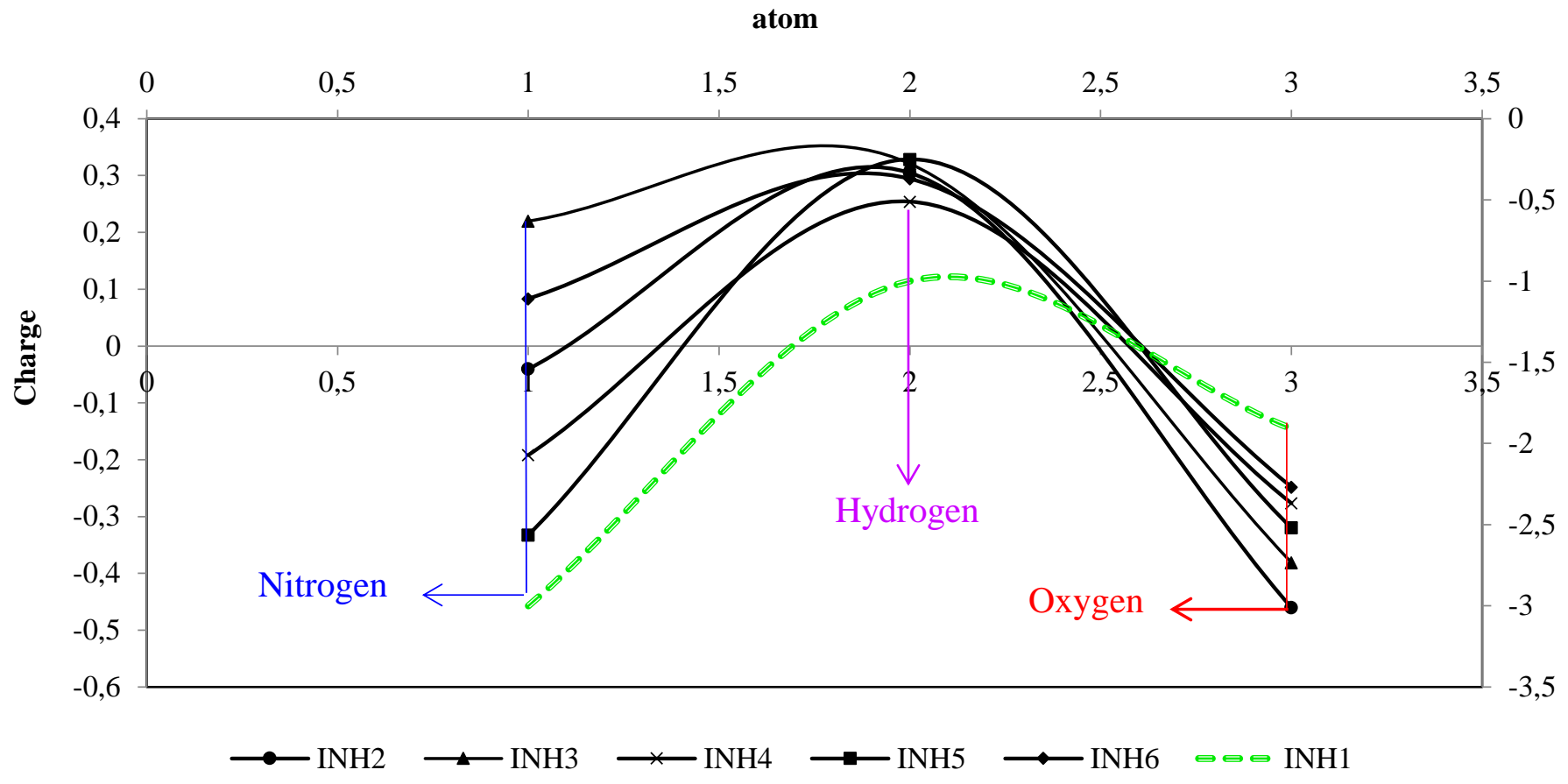

Fig.5. Comparison of atomic charge versus labeled of oxygen, nitrogen and hydrogen atoms in the junction of N-[[4-(4-methylpiperazin-1-yl) phenyl] methyl]-1,2oxazole-5-carboxamide, NSC 158362, JMF 1586, (N-(2-aminoethyl)-1-1ziridine-ethanamine), [(Z)-1-thiophen-2-ylethylideneamino] thiourea and Vanillinbananin with Tyr160-Met161-His162 (inh[1-6]-TMH) in water medium by formation the hydrogen bonding.

Thus the perspective of Fig.5 has recommended the reason for existing observed various results of the atomic charge on inh[1-6]-TMH complexes as the inhibitor-coronavirus which are principally related to the position of active cites of indicated oxygen, nitrogen and hydrogen atoms in the junction of bond angles including; $\mathrm{N}(44) \stackrel{\cdots}{-} \mathrm{H}(67) \cdots$ $\mathrm{N}(77) \stackrel{\cdots}{-} \mathrm{H}(78) \stackrel{\cdots}{=} \mathrm{O}(7), \mathrm{N}(10) \stackrel{\cdots}{-} \mathrm{H}(44) \stackrel{\cdots}{-} \mathrm{O}(43), \mathrm{N}(17) \stackrel{\cdots \cdots}{-} \mathrm{H}(44) \stackrel{\cdots}{-}$ $\mathrm{O}(43), \mathrm{N}(86) \stackrel{\cdots}{-} \mathrm{H}(87) \stackrel{\cdots}{-} \mathrm{O}(7)$ for inh[1-6]-TMH, respectively (see Table 1).

In this work, oxygen and nitrogen atoms as the electronegative atoms contribute the charge of electrons with hydrogen due to formation of H-bonding in water medium with highest negative atomic charge on oxygen and nitrogen to the lowest negative atomic charge as N-[[4-(4-methylpiperazin-1yl)phenyl]methyl]-1,2-oxazole-5-carboxamide (inh1)-TMH> ,[(Z)-1-thiophen2-ylethylideneamino]thiourea (inh5-TMH) $>$ (N-(2-aminoethyl)-1-1ziridineethanamine) (inh4)-TMH> NSC 158362 (inh2)-TMH> Vanillinbananin (inh6)-
TMH> JMF 1586 (inh3)-TMH>, respectively (Fig.5).

In fact, the spin density and partial charges have been obtained by fitting the electrostatic potential to fix the charge of oxygen and nitrogen with high electronegativity in junction of electrophilic group of hydrogen in the structures of inh[1-6]-CoV as the anti-virus drugs which conduct us toward the industry of drug delivery in water medium by formation the $\mathrm{H}$ - bonding.

NMR calculations on the database of amino acids in beta sheet conformation of Tyr160-Met161-His162 and six inhibitors of N-[[4-(4-methylpiperazin-1yl)phenyl]methyl]-1,2-oxazole-5-carboxamide (inh1), NSC 158362 (inh2),JMF 1586 (inh3),(N-(2-aminoethyl)-1-1ziridine-ethanamine) (inh4), [(Z)-1-thiophen2-ylethylideneamino]thiourea (inh5) and Vanillinbananin (inh6) have been estimated to unravel the indicated atoms of $\mathrm{H}, \mathrm{N}, \mathrm{O}$ in the active sites of these anti-virus drugs through the formation of in water medium by formation the hydrogen bonding by indicating the attack zone of TMH (Scheme2a-g).

(a)

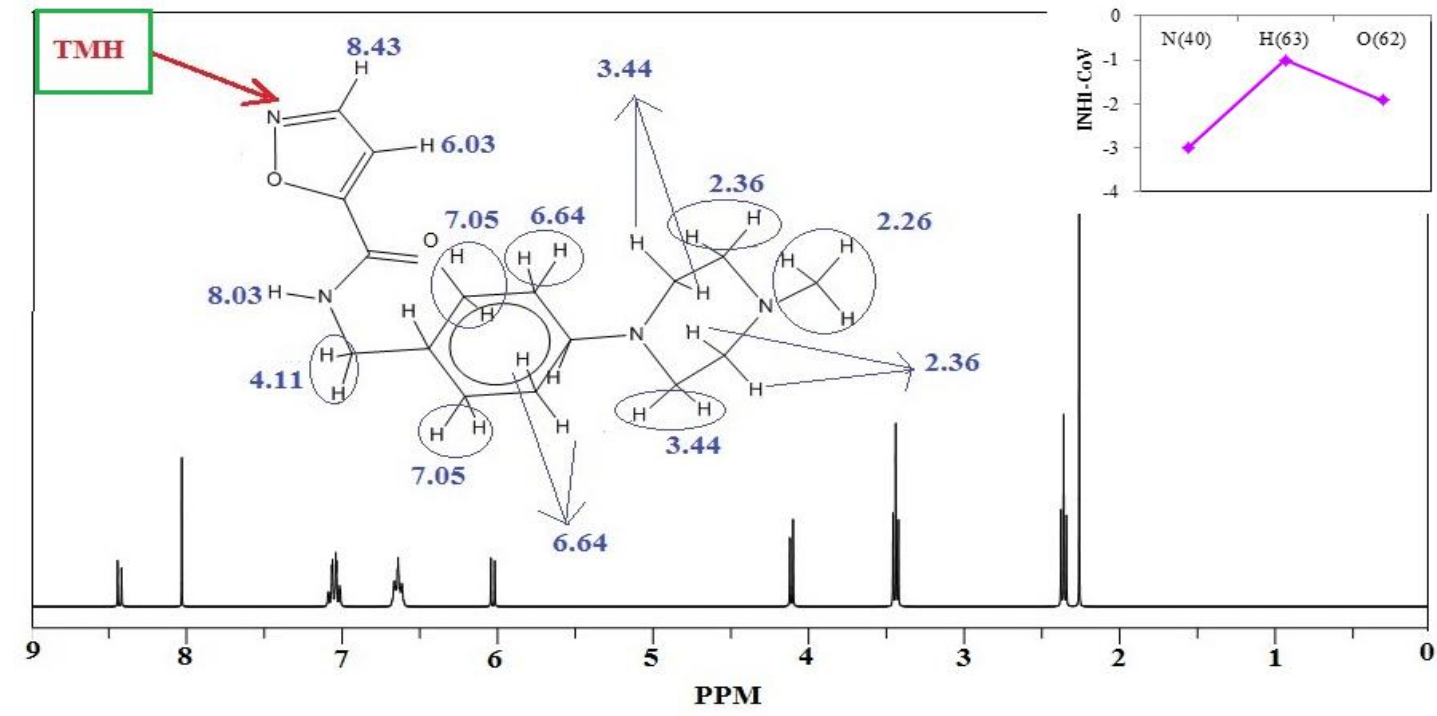


(b)

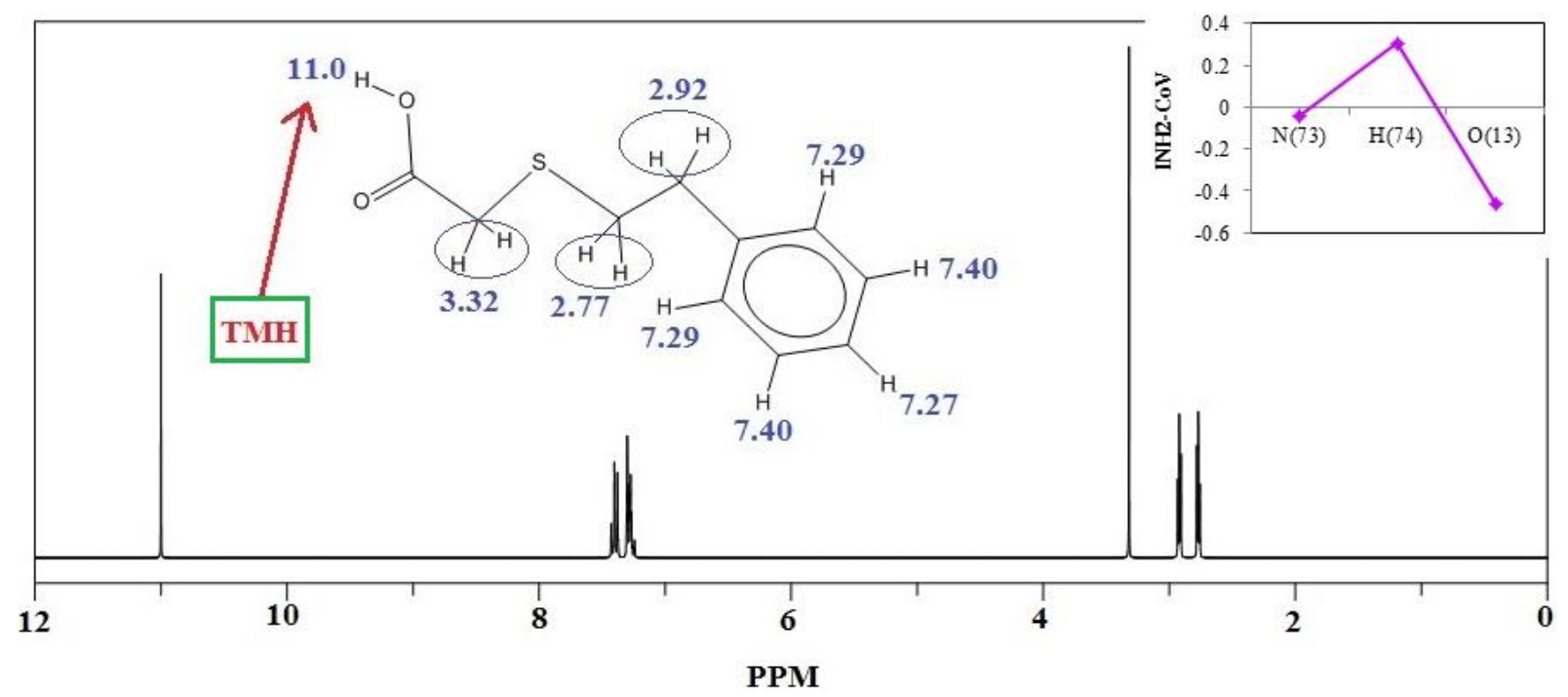

(c)

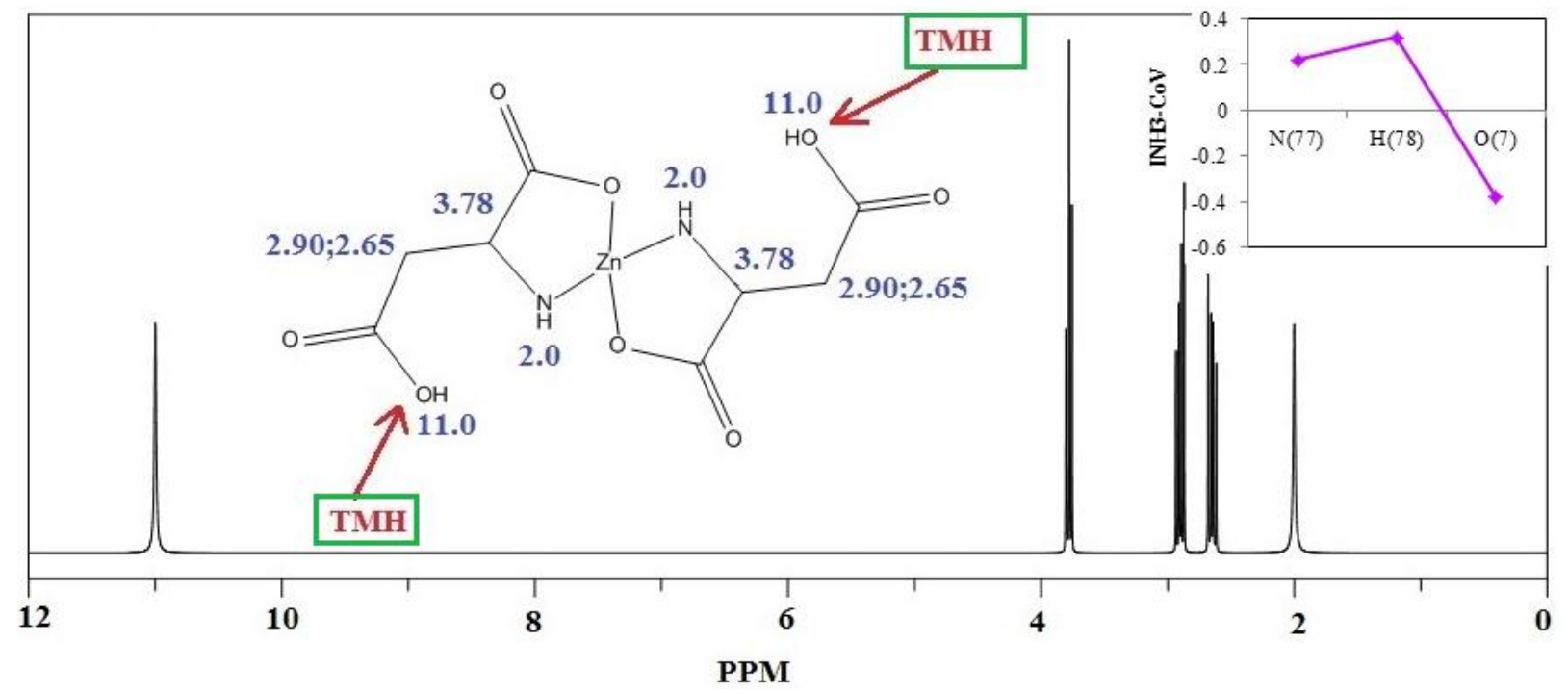

(d)

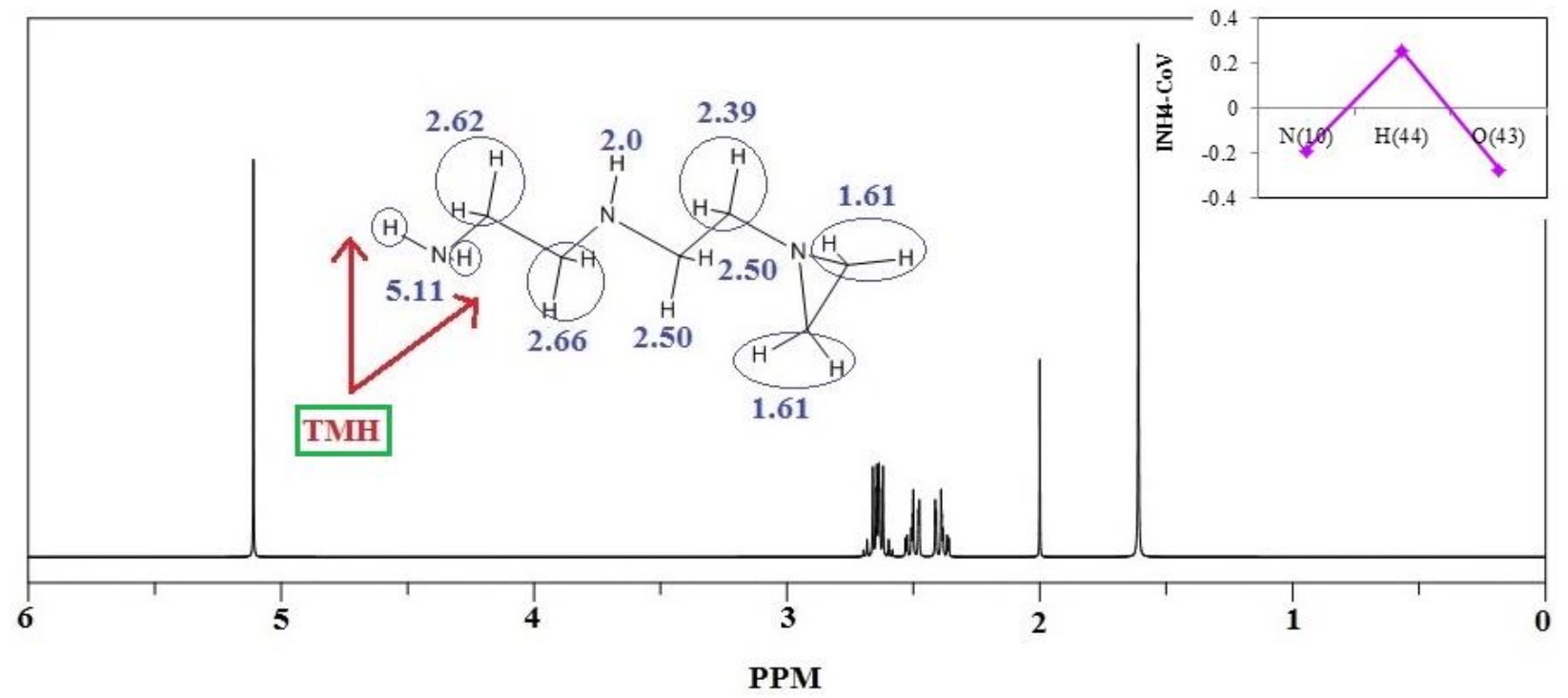


(e)

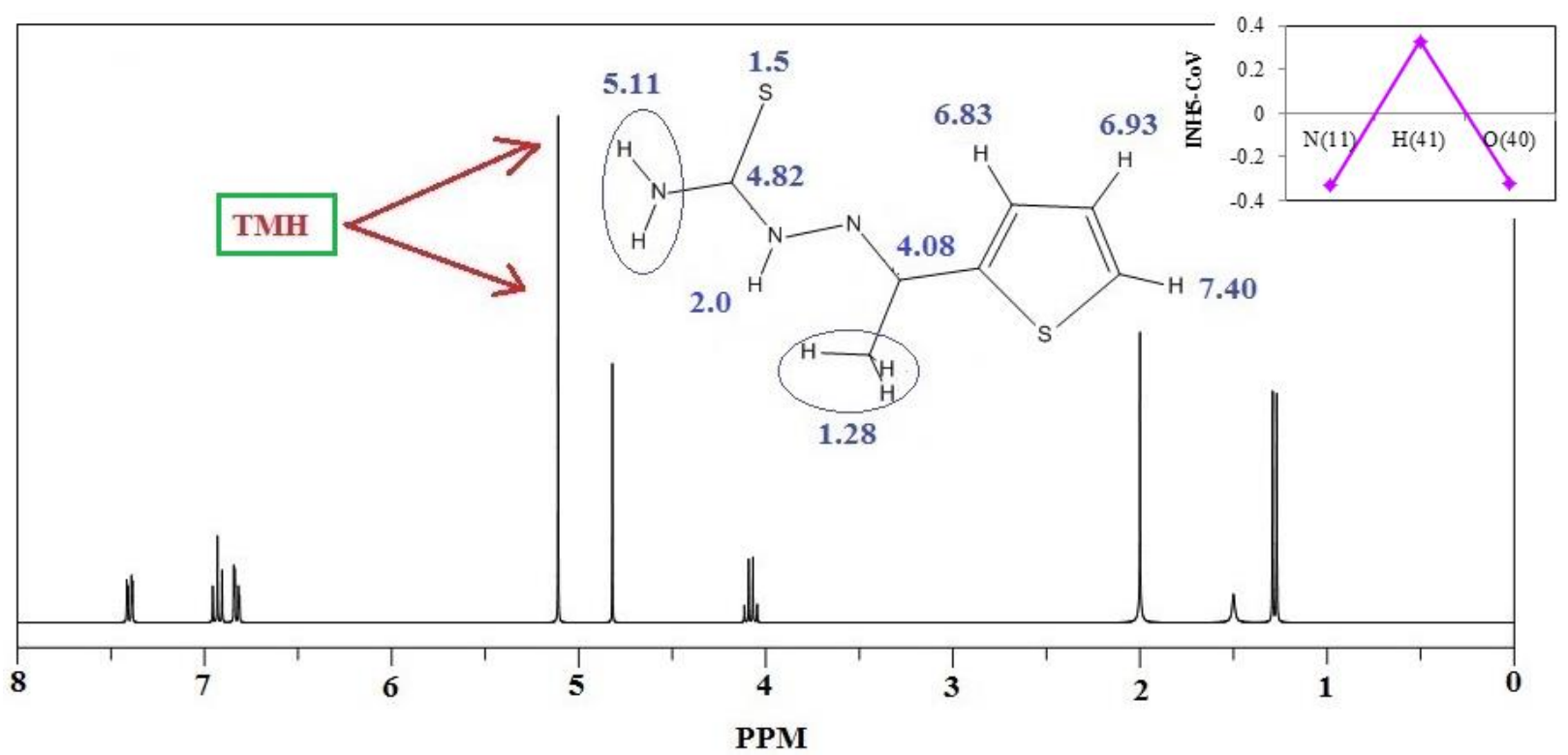

(f)

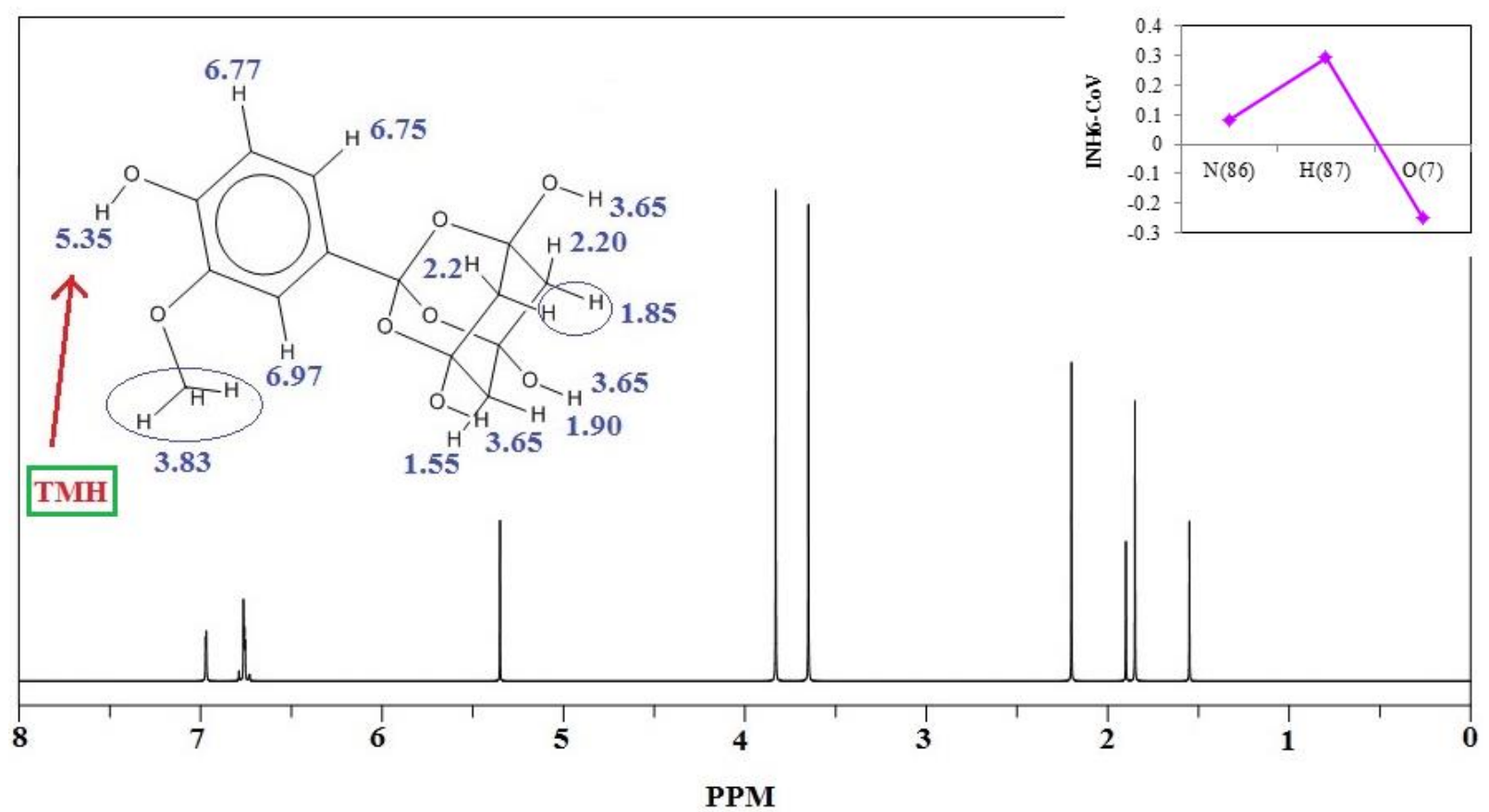

Scheme2. NMR spectra of a)N-[[4-(4-methylpiperazin-1-yl)phenyl]methyl]-1,2-oxazole-5-carboxamide (inh1), b) NSC 158362 (inh2), c) JMF 1586 (inh3), d) (N-(2-aminoethyl)-1-1ziridine-ethanamine) (inh4), e) [(Z)-1-thiophen-2-ylethylideneamino]thiourea (inh5) and f) Vanillinbananin (inh6) by indicating the active zone of TMH in the drug delivery process in water medium by formation the hydrogen bonding.

The NMR measurements demonstrate the active sites of the inhibitors for linking to the Tyr160-Met161-His162 (TMH) in forming the anti-virus drugs while each active atom of oxygen and nitrogen as the electronegative atoms for attaching to the hydrogen denotes the maximal shift in all levels in the NMR spectra (Scheme2).

\section{CONCLUSION}

Generally, inhibitors are capable to join the database amino acids fragment of Tyr160-Met161-His162 as the selective zone of the Coronavirus (CoV) through indicating the shift in their frequency and intensity spectra after estimation by NMR method which are affected by the atomic configuration of the inhibitors.
The stability of H-bonding in water medium between six inhibitors of $\mathrm{N}$-[[4(4-methylpiperazin-1-yl)phenyl]methyl]-1,2-oxazole-5-carboxamide (inh1), NSC 158362 (inh2),JMF 1586 (inh3),(N-(2-aminoethyl)-1-1ziridineethanamine) (inh4) ,[(Z)-1-thiophen-2-ylethylideneamino]thiourea (inh5) and Vanillinbananin (inh6) and coronavirus through the formation Inhibitor- $\mathrm{CoV}$ complexes through two probabilities of $\mathrm{N}=\mathrm{-} \mathrm{H}$ and $\mathrm{O}=\mathrm{-}$ H with different atomic charges has been investigated using IR methods. So, the thermodynamic properties of Gibbs free energy, enthalpy of formation, Electronic Energy, CoreCore interaction have approved the stability of anti-coronavirus complexes of inh[1-6]-TMH through the H-bonding formation in water medium using the drug delivery method. 


\section{REFERENCES}

1. Lai, M. M. C., and K. V. Holmes. 2001. Coronaviridae: the viruses and their replication, p. 1163-1179. In D. M. Knipe and P. M. Howley (ed.), Fields virology, 4th ed. Lippincott Williams \& Wilkins, Philadelphia, PA.

2. Pereira, H. G. 1989. Coronaviridae, In J. S. Porterfield (ed.), ANDREWES' viruses of vertebrates, 5th ed. Bailliere Tindall, London, United Kingdom, $42-57$.

3. Spaan, W. J. M., and D. Cavanagh. 2004. Coronaviridae, In C. M. Fauquet, M. A. Mayo, J. Maniloff, U. Desselberger, and L. A. Ball (ed.), Virus taxonomy: eighth report of the International Committee on Taxonomy of Viruses. Elsevier-Academic Press, London, United Kingdom, 945-962.

4. Ziebuhr, J. 2005. The coronavirus replicase. Curr. Top. Microbiol. Immunol. 287,57-94

5. Rolain, J.M. Colson, P. Raoult, D. 2007. Recycling of chloroquine and its hydroxyl analogue to face bacterial, fungal and viral infections in the $21 \mathrm{st}$ century, Int J Antimicrob Agents, 30, 297-308.

6. Hung, H.M. Yang, S.L. Chen, C.J. Chiu, C.H. Kuo, C.Y. Huang, K.A. et al. 2019.Molecular epidemiology and clinical features of rhinovirus infections among hospitalized patients in a medical center in Taiwan,$J$ Microbiol Immunol Infect, 52, 233-241

7. D. Chang, M. Lin, L. Wei, L. Xie, G. Zhu, C.S. Dela Cruz, et al .2020. Epidemiologic and clinical characteristics of novel coronavirus infections involving 13 patients outside Wuhan, China, JAMA .

8. Lai, Chih-Cheng; Shih, Tzu-Ping; Ko, Wen-Chien; Tang, Hung-Jen; Hsueh, Po-Ren .2020. Severe acute respiratory syndrome coronavirus 2 (SARS$\mathrm{CoV}-2)$ and coronavirus disease-2019 (COVID-19): The epidemic and the challenges. International Journal of Antimicrobial Agents: 105924.

9. Casanova, L.M. Jeon, S. Rutala, W.A. Weber, D.J. SobseyM.D.2020. Eff ects of air temperature and relative humidity on coronavirus survival on surfaces, Appl Environ Microbiol, 76 (2010), 2712-2717.

10. Jiang, S. Du, L. Shi, Z. 2020. An emerging coronavirus causing pneumonia outbreak in Wuhan, China: calling for developing therapeutic and prophylactic strategies, Emerg Microbes Infect, 9, 275-277.

11. Chen, Nanshan; Zhou, Min; Dong, Xuan; Qu, Jieming; Gong, Fengyun; Han, Yang; Qiu, Yang; Wang, Jingli; Liu, Ying; Wei, Yuan; Xia, Jia'an.2020. Epidemiological and clinical characteristics of 99 cases of 2019 novel coronavirus pneumonia in Wuhan, China: a descriptive study. The Lancet. 0 (10223): 507-513.

12. Hessen, Margaret Trexler .2020. Novel Coronavirus Information Center: Expert guidance and commentary. Elsevier Connect. Archived from the original on 30 January 2020. Retrieved 31 January 2020.

13. Ziebuhr J., Herold,J. and Siddell,S.G. 1995.Characterization of a human coronavirus (strain 229E) 3C-like proteinase activity. J. Virol., 69, 43314338.

14. Wuhan Coronavirus Death Rate - Worldometer. www.worldometers.info. Archivedfrom the original on 31 January 2020. Retrieved 2 February 2020.

15. J.F. Chan, K.H. Kok, Z. Zhu, H. Chu, K.K. To, S. Yuan, et al.2020. Genomic characterization of the 2019 novel human-pathogenic coronavirus isolated from a patient with atypical pneumonia after visiting Wuhan, Emerg Microbes Infect, 9,221-236.

16. Ziebuhr J., Heusipp,G. and Siddell,S.G. 1997. Biosynthesis, purification, and characterization of the human coronavirus $229 \mathrm{E}$ 3C-like proteinase. J. Virol., 71, 3992-3997.

17. Drosten, C., Gunther, Preiser, S. W. van der Werf, S. Brodt, H. R. Becker, S. Rabenau, H. Panning, M. Kolesnikova, L. Fouchier, R. A. Berger, Burguiere, A. A. M. Cinatl, J. Eickmann, M. Escriou, N. Grywna, K. Kramme, S. Manuguerra, J. C. Muller, S. Rickerts, V. Sturmer, M. Vieth, S. Klenk, H. D. Osterhaus, A. D. Schmitz, H. and Doerr. H. W. 2003. Identification of a novel coronavirus in patients with severe acute respiratory syndrome. N. Engl.J. Med. 348,1967-1976.

18. Fouchier, R. A., T. Kuiken, M. Schutten, G. van Amerongen, G. J. van Doornum, B. G. van den Hoogen, M. Peiris, W. Lim, K. Stohr, and A. D.Osterhaus. 2003. Aetiology: Koch's postulates fulfilled for SARS virus. Nature .423,240

19. Ksiazek, T. G., D. Erdman, C. S. Goldsmith, S. R. Zaki, T. Peret, S. Emery, S. Tong, C. Urbani, J. A. Comer, W. Lim, P. E. Rollin, S. F. Dowell, A. E.Ling, C. D. Humphrey, W. J. Shieh, J. Guarner, C. D. Paddock, P. Rota, B. Fields, J. DeRisi, J. Y. Yang, N. Cox, J. M. Hughes, J. W. LeDuc, W. J.Bellini, and L. J. Anderson. 2003. A novel coronavirus associated with severe acute respiratory syndrome. N. Engl. J. Med. 348, 1953-1966.

20. Kuiken, T., R. A. Fouchier, M. Schutten, G. F. Rimmelzwaan, G. van Amerongen, D. van Riel, J. D. Laman, T. de Jong, G. van Doornum, W. Lim, A. E.Ling, P. K. Chan, J. S. Tam, M. C. Zambon, R. Gopal, C. Drosten, S. van der Werf, N. Escriou, J. C. Manuguerra, K. Stohr, J. S. Peiris, and A.
D.Osterhaus. 2003. Newly discovered coronavirus as the primary cause of severe acute respiratory syndrome. Lancet. 362,263-270.

21. Peiris, J. S., S. T. Lai, L. L. Poon, Y. Guan, L. Y. Yam, W. Lim, J. Nicholls, W. K. Yee, W. W. Yan, M. T. Cheung, V. C. Cheng, K. H. Chan, D. N. Tsang,R. W. Yung, T. K. Ng, and K. Y. Yuen. 2003. Coronavirus as a possible cause of severe acute respiratory syndrome. Lancet 361, 1319-1325.

22. Hon CC, Lam TY, Shi ZL, Drummond AJ, Yip CW, Zeng F, Lam PY, Leung FC. 2008. Evidence of the recombinant origin of a bat severe acute respiratory syndrome (SARS)-like coronavirus and its implications on the direct ancestor of SARS coronavirus. J Virol. 82,1819-1826.

23. Li W, Shi Z, Yu M, Ren W, Smith C, Epstein JH, Wang H, Crameri G, Hu $\mathrm{Z}$, Zhang $\mathrm{H}$, et al. Bats are natural reservoirs of SARS-like coronaviruses. Science. 2005; 310:676-679.

24. Wang LF, Eaton BT.2007. Bats, civets and the emergence of SARS. Curr Top Microbiol Immunol. 315,325-344.

25. Haagmans BL, Al Dhahiry SH, Reusken CB, Raj VS, Galiano M, Myers R, Godeke GJ, Jonges M, Farag E, Diab A, et al.2014. Middle East respiratory syndrome coronavirus in dromedary camels: an outbreak investigation. Lancet Infect Dis. 14(2):140-5

26. Abdel-Moneim AS.2014. Middle East respiratory syndrome coronavirus (MERS-CoV): evidence and speculations. Arch Virol. 159(7):1575-84

27. Annan A, Baldwin HJ, Corman VM, Klose SM, Owusu M, Nkrumah EE, Badu EK, Anti P, Agbenyega O, Meyer B, et al.2013. Human betacoronavirus 2c EMC/2012-related viruses in bats, Ghana and Europe. Emerg Infect Dis. 19,456-459.

28. Anthony SJ, Ojeda-Flores R, Rico-Chavez O, Navarrete-Macias I, Zambrana-Torrelio CM, Rostal MK, Epstein JH, Tipps T, Liang E, SanchezLeon M, et al.2013. Coronaviruses in bats from Mexico. J Gen Virol. 94,1028-1038

29. Van Boheemen S, de Graaf M, Lauber C, Bestebroer TM, Raj VS, Zaki AM, Osterhaus AD, Haagmans BL, Gorbalenya AE, Snijder EJ, et al.2012. Genomic characterization of a newly discovered coronavirus associated with acute respiratory distress syndrome in humans. MBio. 3(6). e00473-12.

30. Ithete NL, Stoffberg S, Corman VM, Cottontail VM, Richards LR, Schoeman MC, Drosten C, Drexler JF, Preiser W.2013. Close relative of human Middle East respiratory syndrome coronavirus in bat, South Africa. Emerg Infect Dis. 19, 1697-1699.

31. Peiris JS, Yuen KY, Osterhaus AD, Stohr K. The severe acute respiratory syndrome. N Engl J Med. 2003; 349:2431-2441.

32. Russell, C.D. Millar, J.E. BaillieJ.K. 2020. Clinical evidence does not support corticosteroid treatment for 2019-nCoV lung injury ,Lancet. 395 , 473-475.

33. Spaan, W. J. M., and D. Cavanagh. 2004. Coronaviridae, 945-962. In C. M Fauquet, M. A. Mayo, J. Maniloff, U. Desselberger, and L. A. Ball (ed.), Virus taxonomy: eighth report of the International Committee on Taxonomy of Viruses. Elsevier-Academic Press, London, United Kingdom.

34. Cavanagh, D. 2003. Severe acute respiratory syndrome vaccine development: experiences of vaccination against avian infectious bronchitis coronavirus. Avian Pathol. 32,567-582.

35. Ignjatoviæ, J., and S. Sapats. 2000. Avian infectious bronchitis virus. Rev Sci. Tech. 19:493-508.

36. Ziebuhr J., Snijder,E.J. and Gorbalenya,A.E. 2000.Virus-encoded proteinases and proteolytic processing in the Nidovirales. J. Gen. Virol., 81, 853-879.

37. Ryu, S. Chun, B.C.2020. Epidemiological characteristics of 2019 novel coronavirus: an interim review, Epidemiol Health, 42, Article e2020006.

38. Lee, S.H. Ruan, S.Y. Pan, S.C. Lee, T.F. Chien, J.Y.Hsueh P.R.2019. Perf ormance of a multiplex PCR pneumonia panel for the identification of respiratory pathogens and the main determinants of resistance from the lower respiratory tract specimens of adult patients in intensive care units, $J$ Microbiol Immunol Infect, 52 ,920-928.

39. Chen, Nanshan; Zhou, Min; Dong, Xuan; Qu, Jieming; Gong, Fengyun; Han, Yang; Qiu, Yang; Wang, Jingli; Liu, Ying; Wei, Yuan; Xia, Jia'an.2020. Epidemiological and clinical characteristics of 99 cases of 2019 novel coronavirus pneumonia in Wuhan, China: a descriptive study. The Lancet. 0 (10223): 507-513.

40. Vaguine A.A., Richelle,J. and Wodak,S.J. 1999. SFCHECK: a unified set of procedures for evaluating the quality of macromolecular structure-factor data and their agreement with the atomic model. Acta Crystallogr. D, 55, 191205.

41. Vriend G. 1990.WHAT IF: a molecular modeling and drug design program. J. Mol. Graphics, 8, 52-56.

42. Frisch, M.J., Trucks, G.W., Schlegel, H.B., Scuseria, G.E., Robb, M.A., Cheeseman, J.R., Scalmani, G., Barone, V., Mennucci, B., Petersson, G.A., Nakatsuji, H., Caricato, M., Li, X., Hratchian, H.P., Izmaylov, A.F., Bloino, 
J., Zheng, G., Sonnenberg, J.L., Hada, M., Ehara, M., Toyota, K., Fukuda, R., Hasegawa, J., Ishida, M., Nakajima, T., Honda, Y., Kitao, O., Nakai, H., Vreven, T., Montgomery Jr., J.A., Peralta, J.E., Ogliaro, F., Bearpark, M., Heyd, J.J., Brothers, E., Kudin, K.N., Staroverov, V.N., Kobayashi, R., Normand, J., Raghavachari, K., Rendell, A., Burant, J.C., Iyengar, S.S., Tomasi, J., Cossi, M., Rega, N., Millam, J.M., Klene, M., Knox, J.E., Cross, J.B., Bakken, V., Adamo, C., Jaramillo, J., Gomperts, R., Stratmann, R.E., Yazyev, O., Austin, A.J., Cammi, R., Pomelli, C., Ochterski, J.W., Martin, R.L., Morokuma, K., Zakrzewski, V.G., Voth, G.A., Salvador, P., Dannenberg, J.J., Dapprich, S., Daniels, A.D., Farkas, O., Foresman, J.B., Ortiz, J.V., Cioslowski, J. and Fox, D.J. 2010. Gaussian 09, Revision B.01. Gaussian Inc., Wallingford.

43. Mollaamin F., Monajjemi M.,2015. Harmonic Linear Combination and Normal Mode Analysis of Semiconductor Nanotubes Vibrations, Journal of Computational and Theoretical Nanoscience, 12(6), 1030-1039.

44. Wilfred F., Gunsteren V., and Berendsen H.J.C.,1990. Computer Simulation of Molecular Dynamics: Methodology, Applications, and Perspectives in Chemistry, Angewandte Chemie International Edition in English, 29(9), 9921023.

45. Ni W., Li G. , Zhao J., Cui J., Wang R. , Gao Z., Liu Y. 2018. Use of Monte Carlo simulation to evaluate the efficacy of tigecycline and minocycline for the treatment of pneumonia due to carbapenemase-producing Klebsiella pneumoniae. Infect Dis (Lond), ,50(7),507-513.

46. Andrews C.W. , Wisowaty J., Davis A.O., Crouch R.C., Martin G.E.,1995. Molecular modeling, NMR spectroscopy, and conformational analysis of 3', 4'- anhydrovinblastine. Journal of Heterocyclic Chemistry, 32 (3): 10111017.

47. Monajjemi, M. Honarparvar, B. Nasseri, S.M. Khaleghian, M. ,2009. NQR and NMR study of hydrogen bonding interactions in anhydrous and monohydrated guanine cluster model: A computational study, Journal of Structural Chemistry,50(1), pp. 67-77.

48. Monajjemi, M. Ghiasi, R. Seyed Sadjadi, M.A.2003. Metal-stabilized rare tautomers: $\mathrm{N} 4$ metalated cytosine $(\mathrm{M}=\mathrm{Li}, \mathrm{Na}, \mathrm{K}, \mathrm{Rb}$ and $\mathrm{Cs})$, theoretical views, Applied Organometallic Chemistry, 17(8), 635-640.

49. Monajjemi M., Mollaamin F., Gholami M.R. , Yoosbashizadeh H., Sadrnezhad S.K., Passdar H.,2003. Quantum chemical parameters of some organic corrosion inhibitors, pyridine, 2-picoline 4-picoline and 2,4-lutidine, adsorption at aluminum surface in hydrocholoric and nitric acids and comparison between two acidic media, Main Group Metal Chemistry, 26, 349-361.
50. Ghalandari B., Monajjemi M., Mollaamin F.,2011. Theoretical Investigation of Carbon Nanotube Binding to DNA in View of Drug Delivery, Journal of Computational and Theoretical Nanoscience, 2011, 8, 1212-1219.

51. Cohen G. and Eisenberg H.,1968. Deoxyribonucleate solutions: sedimentation in a density gradient, partial specific volumes, density and refractive index increments, and preferential interactions. Biopolymers. 6(8), 1077-100.

52. Beak P., Covington J.B., Smith S.G., White J.M., and Zeiger J.M.,1980. Displacement of protomeric equilibriums by self-association: hydroxypyridine-pyridone and mercaptopyridine-thiopyridone isomer pairs , J. Org. Chem. 45(8),1354-1362.

53. Sarasia E.M., Afsharnezhad S., Honarparvar B., Mollaamin F., Monajjemi M., 2011. Estrogenic active stilbene derivatives as anti-cancer agents: A DFT and QSAR study , Physics and Chemistry of Liquids, 2011, 49, 561-571.

54. Monajjemi M., Mahdavian L., Mollaamin F., Khaleghian M.,2009. Interaction of $\mathrm{Na}, \mathrm{Mg}, \mathrm{Al}, \mathrm{Si}$ with carbon nanotube (CNT): NMR and IR study , Russian Journal of Inorganic Chemistry, 54, 1465-1473.

55. Ardalan, T. Ardalan, P. Monajjemi, M., 2014.Nano theoretical study of a C 16 cluster as a novel material for vitamin C carrier, Fullerenes Nanotubes and Carbon Nanostructures, 22(8), 687-708

56. Kirkwood J.G.,1934. On the Theory of Strong Electrolyte Solutions, J. Chem. Phys. 2, 767 .

57. Kirkwood J.G., 1939. The Dielectric Polarization of Polar Liquids, J. Chem. Phys. 7, 911.

58. Onsager L.,1936 Electric Moments of Molecules in Liquids, J. Am. Chem. Soc. 58(8), 1486-1493.

59. Wong M.A., Frisch M.J., and Wiberg K.B., 1991. Solvent effects.1. The mediation of electrostatic effects by solvents, J. Am. Chem. Soc. 113(13), 4776-4782.

60. Jerzy Cioslowski and Martin Martinov, 1995, Effects of solvation on chemical bonding: An electron-flow analysis, J. Chem. Phys. 103, 4967.

61. Lee, V.S. Nimmanpipug, P. Mollaamin, F.(...), Thanasanvorakun, S. Monajjemi, M.2009. Investigation of single wall carbon nanotubes electrical properties and normal mode analysis: Dielectric effects, Russian Journal of Physical Chemistry A, 83(13), 2288-2296.

62. Monajjemi, M. Farahani, N. Mollaamin, F.2012. Thermodynamic study of solvent effects on nanostructures: Phosphatidylserine and phosphatidylinositol membranes, Physics and Chemistry of Liquids, 50(2), 161-172. 